\title{
Kesesuaian Kualitas Air Irigasi untuk Padi Sawah di Daerah Irigasi Mambal
}

\section{GUSTI NGURAH SANTOSA*) DAN I PUTU DHARMA}

\author{
Program Studi Agroekoteknologi Fakultas Pertanian Universitas Udayana \\ Jl. PB. Sudirman, Denpasar 80231 Bali \\ ${ }^{*}$ E-mail: santosaprofgreen@unud.ac.id
}

\begin{abstract}
Suitability of Irrigation Water Quality for Rice in Mambal Irrigation Area. Mambal irrigation area is located in southern region of Bali, close by urban area. It consists of 42 Subak which covered 4.820 ha. However, the total area that still exists today is only 2.978 ha, and it is considered potential in increasing rice production and supplying rice in order to support food self-sufficiency in Bali. The increase of population is considered as the factor of wetland conversion because, the growth of population leads to variety of purposes such as shelter (housing), tourism/hotel, accommodation, business/home industry, livestock, public facilities, etc. Therefore, the activities done on the wetland conversion area automatically changed. That activity on conversion area consequences in both liquid or solid waste, and it is often discharged into rivers or irrigation channels. Consequently, it may cause irrigation water pollution. Poor quality of irrigation water can endangering rice plant growth and reduce the production, which means blocking or inhibiting food self-sufficiency. This study is considered as field and laboratory research. There are some field activities done, namely observation of the pollution sources and types of pollutants, as well as waste disposal mechanisms and technologies used to tackle pollution. In order to determine the quality of irrigation water, the water samples taken in the primary channel (1 water sample), secondary channel (1 water sample), tertiary channel (1 water sample), and field area (3 samples of water). All water samples are analyzed at the Analytical Laboratory of Udayana University. The results of the study are the sources of pollution come from channel natural environments, public facilities, housing and household waste. It was found that there are some types of waste, namely natural garbage, artificial garbage, liquid or solid waste in small amount. The mechanism of waste disposal is done conventionally and there is no application of technology of waste disposal. The outcome of the study is irrigation water quality for rice is still suitable for irrigation.
\end{abstract}

Keywords: suitability, water quality, rice

PENDAHULUAN

Pangan beras merupakan bahan

makanan pokok utama di Indonesia.
Kekurangan pangan sangat berpengaruh terhadap kesehatan, sekaligus dapat menurunkan kualitas hidup sumberdaya 
I GUSTI NGURAH SANTOSA DAN I PUTU DHARMA. Kesesuaian Kualitas Air Irigasi Untuk Padi...

manusia. Dampak lain yang timbul akibat kekurangan pangan adalah terganggunya stabilitas ekonomi, politik, keamanan dan ketergantungan pada negara lain. Oleh karena itu, ketahanan pangan harus stabil dan tetap terjaga secara berkelanjutan.

Untuk menunjang ketahanan pangan memerlukan debit air yang cukup dan kualitas air irigasi yang sesuai. Salah satu fungsi air terpenting bagi tanaman adalah untuk mengangkut unsur hara dari tanah ke dalam tubuh tanaman (Arifin, 2002). Kualitas air irigasi yang tidak sesuai akan mengganggu pertumbuhan dan menurunkan produksi. Berdasarkan klasifikasi penilaian skor dengan metode Storet, klasifikasi air yang termasuk kelas $\mathrm{D}$, dengan ciri air tercemar berat, dengan nilai Skor >31, memiliki dampak buruk untuk irigasi (Bambang Rahadi dan Novita Lusiana, 2012). Pada keadaan sekarang ini dengan peningkatan jumlah penduduk, maka aktivitaspun akan terus bertambah. Ujung dari aktivitas ini dapat menghasilkan produk yang berupa limbah yang dapat menurunkan atau mencemari air untuk irigasi padi sawah.

Daerah Irigasi Mambal merupakan salah satu Daerah Irigasi di Bali yang terletak di wilayah Bali Selatan. Wilayahnya sebagian besar dekat perkotaan menyebar dari Bendung Mambal sampai ke Pantai.
Tanaman utama yang diusahakan adalah Padi Sawah dengan frekuensi tanam rata rata dua kali setahun. Daerah Irigasi Mambal terdiri dari 42 Subak dan sudah banyak terjadi alih fungsi lahan. Sebagai contoh hasil penelitian menunjukkan bahwa keberadaan lahan sawah tahun 1980 - 2000 seluas 4.820 ha dan pada tahun 2000 - 2008 menjadi 2.980 ha (Santosa dkk., 2010). Ini berarti sudah terjadi alih fungsi lahan seluas 1.840 ha atau sekitar $38,17 \%$ dari luas semula.

Terjadinya alih fungsi lahan ini sebagai akibat dari meningkatnya jumlah penduduk yang senantiasa dibarengi dengan meningkatnya kebutuhan di luar sektor non pertanian, seperti untuk pemukiman, pariwisata/hotel, fasilitas umum, industri rumah tangga, peternakan dan peruntukan lainnya. Dengan adanya perubahan pemanfaatan ini akan menghasilkan limbah, baik padat, cair atau berupa sampah yang kerapkali dibuang ke sungai atau saluran irigasi. Karena aktivitas manusia di wilayah Daerah Irigasi terus berlanjut maka pembuangan ini juga terus terjadi secara berkelanjutan.

Lahan sawah di Daerah Irigasi Mambal mendapat air irigasi dari Bendung Mambal. Air irigasi sebelum sampai di petakan sawah melalui alur jaringan irigasi yang panjang. Air Selama dalam penyaluran sebelum 
sampai di petakan sawah sangat berpeluang untuk bercampur dengan limbah yang berasal dari buangan berbagai sumber seperti yang sudah disebutkan di atas. Sumber pencemar belum tentu memiliki teknologi pengelolaan limbah, kondisi seperti ini akan memeberikan peluang terjadinya peningkatan pencemaran. Maka fokus perhatian terhadap kualitas air yang sudah bercampur dengan limbah yang akan digunakan untuk irigasi menjadi sangat penting. Kebetulan saat ini petani (warga subak) di wilayah Daerah Irigasi Mambal belum mengetahui apakah air irigasinya masih sesuai atau tidak untuk irigasi. Dalam pikiran mereka selalu ada kekhawatiran terhadap kualitas air irigasi yang digunakan. Berdasarkan kenyataan ini, perlu dilakukan penelitian kualitas air irigasi di Daerah Irigasi Mambal.

Penelititian bertujuan untuk : (a) Mempelajari sumber pencemar, jenis pencemar, mekanisme pembuangan limbah dan teknologi pengelolaan limbah, dan (b) Mengetahui kesesuaian/kelayakan kualitas air irigasi Daerah Irigasi Bendung Mambal.

\section{BAHAN DAN METODE}

Lokasi penelitian adalah di Daerah Irigasi Mambal, Kabupaten Badung dengan durasi waktu mulai dari bulan April 2016 sampai dengan bulan Oktober 2016.
Penelitian ini dilakukan pada saluran irigasi primer, sekunder dan tersier dan di petakan sawah subak. Bahan dan Alat yang digunakan pada penelitian ini adalah air, fasilitas irigasi di Daerah Irigasi Mambal, Jerigen, Ember, Meteran, Tali, Gunting dan alat-alat tulis. Untuk di lab bahan dan alat meliputi zat kimia dan peralatan analisa air.

Pada kawasan Daerah Irigasi Mambal terdapat perumahan, pemukiman, pariwisata, fasilitas umum dan peruntukan lainnya. Fasilitas-fasilitas ini keberadaannya sangat dekat atau berdampingan dengan wilyah subak dan fasilitas irigasinya. Keberadaan wilayah subak dan desa dinas (administratif) hampir jadi satu. Demikian djuga dengan penduduknya, anggota subak dan penduduk desa dinas menyatu. Secara realita di lapangan subak, masyarakat, dan pemerintah hubungannya sangat dekat, tidak bisa dipisahkan, menyatu menjadi satu paket.

Penelitian ini merupakan penelitian lapangan dan laboratorium. Kegiatan di lapangan meliputi pengamatan terhadap sumber pencemar, jenis pencemar (sampah alamiah berupa ranting pohon, dedaunan, rumput; sampah buatan, limbah cair dan padat), mekanisme pembuangan limbah dan teknologi yang digunakan untuk mengatasi pencemaran tersebut. Untuk mengetahui kelayakan kualitas air untuk irigasi untuk 
I GUSTI NGURAH SANTOSA DAN I PUTU DHARMA. Kesesuaian Kualitas Air Irigasi Untuk Padi...

padi sawah (penelitian laboratorium), maka di Daerah Irigasi Mambal diambil sampel air. Pengambilan sampel dilakukan pada musim kemarau, pada siang hari dengan menyusuri Daerah Irigasi Mambal dari hulu ke hilir yaitu dari Bangunan Bendung, Bangunan Bagi, Saluran sampai ke petakan sawah subak. Untuk di saluran, sampel air diambil pada keadaan air sedang mengalir, di bagian tengah saluran dan di bawah permukaan air dan di atas dasar saluran.

Sampel air diambil di Saluran Primer (1 Sampel air), Saluran Sekunder (1 Sampel air), Saluran Tersier (1 Sampel air) dan di petakan sawah (3 Sampel air) yaitu masingmasing di Subak Basang Kase, Subak Tegal dan Subak Moding. Sampel air yang sudah diambil langsung dibawa ke Laboratorium Analitik Universitas Udayana untuk dianalisa. Parameter kualitas air yang ditentukan di laboratorium adalah Konduktivitas atau Daya Hantar Listrik (DHL), Padatan terlarut (TDS), Kemasaman (pH), Kalsium (Ca), Magnesium (Mg), Natrium (Na), Karbonat (CO3), Bikarbonat (HCO3), Sulfat (SO4), Klorida (Cl), Kalium (K), Nitrat (NO3) dan Boron (B)

Penentuan kelayakan kualitas air untuk irigasi dengan membandingkan nilai parameter yang sudah dianalisa dicocokan dengan standar yang sudah ada, berdasarkan
Project Management Unit (1996, dalam Santosa, 2006). Acuan yang digunakan adalah apabila nilai parameter analisa laboratorium masih masuk dalam kisaran atau lebih rendah dari batas atas standar, maka kualitas air tersebut dinyatakan layak untuk irigasi atau sebaliknya. Sebagai contoh untuk sodium $(\mathrm{Na})$ batasan untuk irigasi 0-40 me/l, kalau hasil analisa laboratorium diperoleh misalnya 30 me/l maka kualitas air irigasi tersebut ditinjau dari segi sodium $(\mathrm{Na})$ layak untuk irigasi. Cara penentuan kelayakan untuk parameter lainnya juga sama demikian.

\section{HASIL DAN PEMBAHASAN}

\section{Penelitian Lapangan}

Daerah Irigasi Mambal (areal persawahan) mendapat air dari Bendung Mambal. Berdasarkan pengamatan di lapangan sumber pencemar berasal dari : lingkungan alami saluran, fasilitas umum, perumahan, pertokoan dan limbah rumah tangga. Jenis pencemarnya berupa : lumpur, sampah alamiah (berupa ranting pohon, dedaunan dan rumput), sampah buatan, limbah cair dan padat. Mekanisme pembuangan limbah masih dilakukan secara konvensional, dan belum ada penerapan teknologi untuk pembuangan limbah. 
Untuk di Saluran Primer yang letaknya di bagian hulu Daerah Irigasi, sumber pencemar hampir semuanya berasal dari lingkungan alami saluran, demikian juga halnya dengan saluran Sekunder. Lokasi bangunan letaknya jauh dari saluran, sehingga terhindar dari buangan sampah dan atau limbah. Jenis pencemarnya hanya berupa dedaunan, ranting pohon dalam jumlah yang sangat sedikit, dan dominan lumpur. Pada saluran sekunder terlihat kondisi air lebih keruh dibandingkan dengan saluran primer, warna air terlihat kuning kecoklatan. Keadaan ini disebabkan karena saluran sekunder berada di hilir saluran primer, sehingga jumlah lumpur menjadi lebih terakumulasi. Warna air yang berwarna kuning kecoklatan, kemungkinan juga disebakan di daerah hulu ada aktivitas mengolah tanah pada saat pengambilan sampel dan buangan airnya di alirkan ke saluran irigasi.

Di saluran tersier yang dekat pemukiman jenis pencemar dominan sampah dan ada juga limbah, warna air terlihat kehitaman. Warna air kehitaman ini disebabkan oleh hasil pembusukan sampah yang ada di saluran. Kondisi air di petakan sawah pada areal subak yang terletak di hilir,. dimana sudah banyak ada pemukiman, warna air hampir sama dengan kondisi air yang ada di saluran tersier. Sedangkan pada petakan sawah dimana pemukinan masih jarang, warna air kelihatan lebih jernih. Terkait dengan kondisi ini perlu dilakukan konservasi sumberdaya air. Strategi konservasi sumberdaya air dapat dikelola berdasarkan ruang, aspek hidrologi, pengelolaan air secara tertintegrasi dan kebijakan pemerintah. Konservasi sumberdaya air merupakan faktor utama untuk menunjang penggunaan air secara berkelanjutan, ketahanan pangan dan kemiskinan (Santosa, 2008). Gambar Bendung Mambal yang merupakan sumber air untuk Daerah Irigasi Mambal dapat dilihat pada Gambar 1. 
I GUSTI NGURAH SANTOSA DAN I PUTU DHARMA. Kesesuaian Kualitas Air Irigasi Untuk Padi...

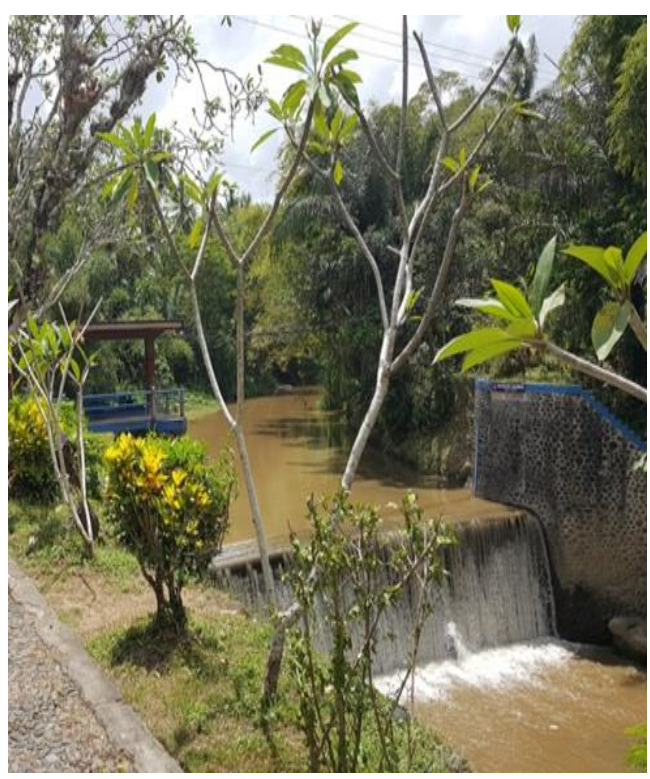

Gambar 1. Bendung Mambal, Sumber Air Areal Sawah Daerah Irigasi Mambal

\section{Penelitian Laboratorium}

Kualitas air irigasi Daerah Irigasi Mambal di Saluran Primer, Saluran Sekunder dan Saluran Tersier disajikan pada Tabel 1.

Tabel 1. Kualitas Air Irigasi di Saluran Primer, Sekunder dan Saluran Tersier Dibandingkan dengan Batasan Irigasi Menurut Project Management Unit (1996, dalam Santosa,2006)

\begin{tabular}{|c|c|c|c|c|c|c|}
\hline No. & Uraian & Satuan & $\begin{array}{c}\text { Batasan } \\
\text { Irigasi }\end{array}$ & $\begin{array}{c}\text { Saluran Primer } \\
\text { (Sal I) }\end{array}$ & $\begin{array}{c}\text { Saluran } \\
\text { Sekunder } \\
\text { (Sal II) }\end{array}$ & $\begin{array}{c}\text { Saluran } \\
\text { Tersier } \\
\text { (Sal III) }\end{array}$ \\
\hline 1. & $\begin{array}{l}\text { Daya Hantar Listrik } \\
\text { (DHL) }\end{array}$ & $\mathrm{mmho} / \mathrm{cm}$ & $0-3$ & 0,500 & 0,594 & 0,641 \\
\hline 2. & $\begin{array}{l}\text { Zat Padat Terlarut } \\
\text { (TDS) }\end{array}$ & $\mathrm{mg} / \mathrm{l}$ & $0-2000$ & 320 & 380 & 410 \\
\hline 3. & $\begin{array}{l}\text { Derajat Keasaman } \\
(\mathrm{pH})\end{array}$ & - & $6,5-8,4$ & 8,33 & 8,13 & 7,4 \\
\hline 4. & Calcium $\left(\mathrm{Ca}^{++}\right)$ & $\mathrm{me} / \mathrm{l}$ & $0-20$ & 0,0125 & 0,015 & 0,035 \\
\hline 5. & Magnesium $\left(\mathrm{Mg}^{++}\right)$ & $\mathrm{me} / \mathrm{l}$ & $0-5$ & 0,15 & 0,1766 & 0,1941 \\
\hline 6. & Sodium $\left(\mathrm{Na}^{++}\right)$ & $\mathrm{me} / \mathrm{l}$ & $0-40$ & 0,0782 & 0,1 & 0,1 \\
\hline 7. & Bicarbonat (HCO3-) & $\mathrm{me} / \mathrm{l}$ & $0-10$ & 2,0170 & 2,367 & 2,192 \\
\hline 8. & Karbonat $\left(\mathrm{CO}^{=}\right)$ & $\mathrm{me} / \mathrm{l}$ & $0-0,1$ & $\mathrm{ttd}$ & ttd & Ttd \\
\hline 9. & Sulfat $\left(\mathrm{SO}^{2}=\right)$ & $\mathrm{me} / \mathrm{l}$ & $0-20$ & 0,3237 & 0,3740 & 0,7658 \\
\hline 10. & Chlorida $\left(\mathrm{Cl}^{-}\right)$ & $\mathrm{me} / \mathrm{l}$ & $0-30$ & 0,3936 & 0,3492 & 0,6252 \\
\hline 11. & Potasium $\left(\mathrm{K}^{+}\right)$ & $\mathrm{mg} / \mathrm{l}$ & $0-2$ & 0,0248 & 0,041 & 0,0441 \\
\hline 12. & Nitrat-Nitrogen (NO3- & $\mathrm{mg} / \mathrm{l}$ & $0-10$ & 3,482 & 5,278 & 5,037 \\
\hline 13. & Boron & $\mathrm{mg} / \mathrm{l}$ & $0-2$ & 0,040 & 0,071 & 0,082 \\
\hline
\end{tabular}

Sumber : Hasil analisa Laboratorium Analitik Universitas Udayana (Oktober 2016). 
Pada Tabel 1 menunjukkan bahwa semua parameter yang diamati bila dibandingkan dengan standar (batasan irigasi) masih layak untuk irigasi. Namun terdapat kecenderungan bahwa semakin ke hilir ternyata nilai semua parameter semakin tinggi. Sebagai contoh untuk nilai Sulfat (SO4) di Saluran Primer nilainya 0,3237 me/l, di Saluran Sekunder 0,3740 me/l dan di Saluran Tersier 0,7648 me/l. Hal ini menunjukkan bahwa semakin ke hilir terjadi lebih banyak akumulasi dari unsur (parameter) yang diamati yang diduga bersumber dari buangan limbah padat atau cair dari di sepanjang atau sekitar saluran. Meskipun demikian nilai sebesar 0,7648 me/l masih sangat layak untuk irigasi karena batas ambang untuk irigasi nilainya adalah 0-20 me/l. Untuk ke depan perlu memperhatikan peraturan pemerintah No 82/2001 (PP 82/2001) yang isinya memfokuskan pada pengelolaan kualitas air dan pengendalian polusi air. Sumber-sumber yang merupakan pencemar perlu melakukan pengelolaan limbah sebelum dibuang ke badan air. Limbah yang dibuang ke badan air sudah memenuhi standar yang sudah ditentukan sehingga tidak menimbulkan pencemaran, dalam hal ini sangat relevan dengan studi pengelolaan sumberdaya air.

Dimasa mendatang pemanfaatan atau penggunaan lahan di Daerah Irigasi Mambal dan kegiatan penduduknya akan terus berkembang yang sifatnya dinamis. Penggunaan lahan seperti untuk pemukiman, pariwisata, industri dan kegiatan lainnya sudah tentu akan menghasilkan sampah atau limbah. Agar kualitas air irgasi tetap terjaga dan dapat digunakan untuk irigasi secara berkelanjutan, maka sangat perlu adanya koordinasi secara berkelanjutan antara Subak, Masyarakat dan Pemerintah khususnya Dinas Pekerjaan Umum terkait pengelolaan sampah dan atau limbah.

Selanjutanya Contoh Gambar petakan sawah tempat mengambil sampel air yang akan ditentukan kualitas airnya seperti pada Gambar 2. Areal persawahan merupakan lokasi paling hilir tempat mengambil sampel air.

Kualitas air irigasi di petakan sawah pada areal Subak Daerah Irigasi Mambal disajikan pada Tabel 2. 
I GUSTI NGURAH SANTOSA DAN I PUTU DHARMA. Kesesuaian Kualitas Air Irigasi Untuk Padi...

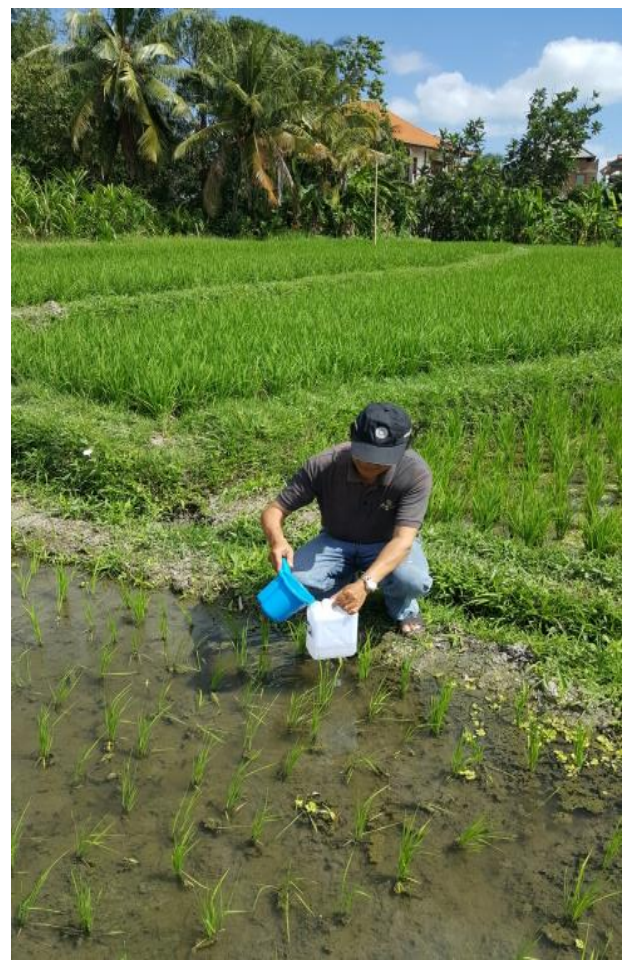

Gambar 2. Pengambilan Sampel Air di Petakan Sawah

Tabel 2. Jenis Parasitoid pada Tanaman Belimbing

\begin{tabular}{|c|c|c|c|c|c|c|}
\hline No. & Uraian & Satuan & $\begin{array}{l}\text { Batasan } \\
\text { Irigasi }\end{array}$ & $\begin{array}{l}\text { Petak Sawah } \\
\text { Subak Basang } \\
\text { Kase }\end{array}$ & $\begin{array}{l}\text { Petak Sawah } \\
\text { Subak Tegal }\end{array}$ & $\begin{array}{l}\text { Petak Sawah } \\
\text { Subak } \\
\text { Moding }\end{array}$ \\
\hline 1. & $\begin{array}{l}\text { Daya Hantar Listrik } \\
\text { (DHL) }\end{array}$ & $\mathrm{mmho} / \mathrm{cm}$ & $0-3$ & 0,594 & 0,578 & 0,531 \\
\hline 2. & $\begin{array}{l}\text { Zat Padat Terlarut } \\
\text { (TDS) }\end{array}$ & $\mathrm{mg} / \mathrm{l}$ & $0-2000$ & 380 & 370 & 340 \\
\hline 3. & $\begin{array}{l}\text { Derajat Keasaman } \\
(\mathrm{pH})\end{array}$ & - & $6,5-8,4$ & 8,14 & 8,80 & 7,98 \\
\hline 4. & Calcium $\left(\mathrm{Ca}^{++}\right)$ & me/l & $0-20$ & 0,02 & 0,016 & 0,0135 \\
\hline 5. & Magnesium $\left(\mathrm{Mg}^{++}\right)$ & $\mathrm{me} / \mathrm{l}$ & $0-5$ & 0,1833 & 0,1925 & 0,1841 \\
\hline 6. & Sodium $\left(\mathrm{Na}^{++}\right)$ & $\mathrm{me} / \mathrm{l}$ & $0-40$ & 0,1 & 0,0969 & 0,0826 \\
\hline 7. & Bicarbonat (HCO3-) & $\mathrm{me} / \mathrm{l}$ & $0-10$ & 1,9732 & 1,7978 & 1,9293 \\
\hline 8. & Karbonat $\left(\mathrm{CO}^{=}\right)$ & $\mathrm{me} / \mathrm{l}$ & $0-0,1$ & $\mathrm{ttd}$ & $\mathrm{ttd}$ & $\mathrm{ttd}$ \\
\hline 9. & Sulfat (SO4=) & $\mathrm{me} / \mathrm{l}$ & $0-20$ & 0,9696 & 0,1823 & 0,5499 \\
\hline 10. & Chlorida $\left(\mathrm{Cl}^{-}\right)$ & $\mathrm{me} / \mathrm{l}$ & $0-30$ & 0,6484 & 0,4632 & 0,4863 \\
\hline 11. & Potasium $\left(\mathrm{K}^{+}\right)$ & $\mathrm{mg} / \mathrm{l}$ & $0-2$ & 0,0382 & 0,0369 & 0,0315 \\
\hline 12. & $\begin{array}{l}\text { Nitrat-Nitrogen } \\
\left(\mathrm{NO}^{-}\right)\end{array}$ & $\mathrm{mg} / \mathrm{l}$ & $0-10$ & 2,407 & 1,498 & 5,672 \\
\hline 13. & Boron & $\mathrm{mg} / \mathrm{l}$ & $0-2$ & 0,060 & 0,054 & 0,049 \\
\hline
\end{tabular}

Sumber : Hasil analisa Laboratorium Analitik Universitas Udayana (Oktober, 2016) 
Kalau diperhatikan pada Tabel 2, juga terlihat bahwa kualitas air untuk ke tiga Subak untuk semua parameter yang diamati masih sangat layak untuk irigasi. Kecuali pada nilai keasaman $(\mathrm{pH})$ di petak sawah Subak Tegal nilainya mencapai 8,80 padahal batas ambang untuk irigasi adalah 6,5 - 8,4. Hal ini ke depan memerlukan pendalaman penelitian terkait dengan kandungan limbah yang dibuang ke saluran. Antisipasi yang baik adalah hendaknya limbah yang dibuang ke saluran sebelumnya sudah dikelola sampai pada batas kelayakan untuk irigasi, Setelah itu baru boleh di buang ke sungai/saluran. Berdasarkan Standar Kualitas Air Nasional (SKAN)(Pemerintah Provinsi Bali, 2007) menyatakan bahwa kualitas air yang termasuk kelas IV diperuntukkan untuk irigasi.

Untuk antisipasi di lapangan dapat dilakukan melalui aplikasi teknik budidaya, misalnya melalui pemberian pupuk yang bersifat asam untuk menurunkan sifat basa seperti halnya dengan pemberian pupuk urea. Terkait dengan semua parameter lainnya, sekalipun pada saat ini masih layak untuk irigasi namun ke depan harus tetap dijaga biar senantiasa kualitas air irigasi tetap layak untuk irikgasi secara berkelanjutan. Pada penelitian sebelumnya yang di lakukan pada saluran tersier di Subak Sempidi, yang juga terletak di Daerah Irigasi Mambal, ternyata kualitas air irigasi masih layak untuk irigasi (Santosa dkk, 2015).

\section{SIMPULAN}

Sumber pencemar air irigasi bersumber dari lingkungan alami saluran, fasilitas umum, perumahan, pertokoan dan limbah rumah tangga. Jenis pencemar meliputi lumpur, sampah alamiah (ranting pohon, dedaunan dan rumput), sampah buatan, limbah cair dan padat. Mekanisme pembuangan limbah dilakukan secara konvensional. Belum ada penerapan teknologi untuk pembuangan limbah. Kualitas air irigasi Daerah Irigasi Mambal masih layak/sesuai untuk irigasi.

Perlu melakukan penelitian lanjutan dengan pengambilan sampel air pada lokasi dan musim yang berbeda yaitu musim hujan dengan jumlah yang lebih banyak. Perlu tetap dijalin kerjasama yang sinergi dan berkelanjutan antara pihak Subak, Pemerintah, dan Masyarakat terkait pengelolaan sampah dan limbah sehingga kualitas air irigasi tetap terjaga.

\section{DAFTAR PUSTAKA}

Ariffin. 2002. Cekaman Air dan Kehidupan Tanaman. Unit Penerbitan Fakultas Pertanian Universitas Brawijaya. 
I GUSTI NGURAH SANTOSA DAN I PUTU DHARMA. Kesesuaian Kualitas Air Irigasi Untuk Padi...

Bambang Rahadi dan Novia Lusiana, 2012. Penentuan Kualitas Air Tanah Dangkal dan Arahan Pengelolaan (Studi Kasus Kabupaten Sumenep). Jurnal Teknologi Pertanian Vol. 13 No.2. Universitas Brawijaya- Malang.

RI (Republik Indonesia). 2001. Peraturan Pemerintah Republik Indonesia Nomor 82 Tahun 2001 tentang Pengelolaan Kualitas Air dan Pengendalian Pencemaran Air. Pemerintah Republik Indonesia.

Pemerintah Provinsi Bali. 2007. Peraturan Gubernur Bali No. 08Tahun 2007, tentang Baku Mutu Lingkungan Hidup dan Kriteria Baku Kerusakan Lingkungan Hidup. Pemerintah Provinsi Bali.

Santosa. I G.N. 2006. Perencanaan Pola Tanam Berdasarkan Kebutuhan dan Persediaan Air pada Lahan Kering di Bali Utara. Disertasi. Program Pascasarjana Universitas Brawijaya.

Santosa. I G.N. 2008. Conservation of Water Resources is as the Key to Realize Sustainable Water Use, Food Security and Poverty Alleviation. Proceedings INWEPF $5^{\text {th }}$ Steering Meeting and Symposium on Efficient and aSustainable Water Use to Address Poverty Alleviation and Food Security. Directorate General of Water Resources Ministry of Public Works Republic of Indonesia - International Network for Water and Ecosystem in Paddy Field.

Santosa, I G.N, Menaka Adnyana, G. Kartha Dinata, I K. dan Gunadi, I G.A. 2010. Dampak Alih Fungsi Lahan Sawah Terhadap Pemanfaatan Sumberdaya Air untuk Menunjang Ketahanan Pangan. Bumi Lestari. Jurnal Lingkungan Hidup. Pusat Penelitian Lingkungan Hidup Lembaga Penelitian Universitas Udayana. Denpasar.
Santosa, I G.N., Menaka Adnyana, G., Artha, I.N., dan I N. Sutedja. 2015. Laporan Pengabdian Masyarakat, Pendidikan dan Pelatihan Strategi Mempertahankan Kualitas Air Irigasi yang Sesuai untuk Padi Sawah di Subak Sempidi. PS Agroekoteknologi Fakultas Pertanian, Universitas Udayana. 